Running head: DECENT AND MODIFICATION OF THE SOCIAL PRIMING PARADIGM

The Descent with Modification of a Social Priming Paradigm. Tracing Srull \& Wyer (1979) forward Åse $\mathrm{H}$ Innes-Ker Lund University

Author note:

Åse $\mathrm{H}$ Innes-Ker, Department of Psychology, Lund University.

Thanks to Richard Harper who provided the title.

The article is based on a series of blog-posts from 2015-16 published in ...not that kind of psychologist

Correspondence concerning this article sould be addressed to Åse $\mathrm{H}$ Innes-Ker, Department of Psychology, Lund University, Box 213, 22100 Lund. E-mail: ase.innes-ker@psy.lu.se 
Running head: DECENT AND MODIFICATION OF THE SOCIAL PRIMING PARADIGM

\begin{abstract}
Adapting a time-line technique loosely based on historical research, I retrieved all papers that cited Srull \& Wyer (1979) the first five years after publication, resulting in 53 papers. Of these 37 reported experiments, 8 were theoretical papers, 6 reviews and 2 other. Eleven of the experimental papers loosely extended the priming work, 22 reported work related to person perception without involving priming, and 20 reported work only obliquely related to the paper.

Extending papers cited $\mathrm{S} \& \mathrm{~W}$ multiple times, whereas those that did not tended to cite the paper only once. Citations had different functions from being peripheral to the argument to being central to the work. All citations were appropriate, and appeared to have interpreted the original research correctly.

The eleven extending papers give a broad but non-systematic impression. The number of participants and observations are low. Most experiments are between subjects. Although the priming in $S \& W$ is strong, subsequent work quickly move toward priming techniques that are either subtle or designed to take place outside awareness. An r-index analysis of all extending papers suggests that expected reproducibility is low.
\end{abstract}

Keywords: Social Priming, timeline research, reproducibility, research-aggregation 
Running head: DECENT AND MODIFICATION OF THE SOCIAL PRIMING PARADIGM

\section{The Descent with Modification of a Social Priming Paradigm. Tracing Srull \& Wyer (1979) forward}

I'm becoming increasingly interested in taking a closer look at the methods and statistics of papers we consider classic, but perhaps don't spend enough time reading and digesting. They have become evidence that we cite, without being entirely clear about what they are showing. In essence, we have formed an impression about them, and are no longer accessing the originals (to paraphrase the logic behind priming and impression formation). This, in turn (as Srull \& Wyer, 1979 point out), could lead to making inferences about what was tested that are not factual.

I'm not the first suggesting that the older literature must be given a second look. There are critiques of Milgram, Zimbardo and the Kitty Genovese lore (Jarret 2008). James Coyne (2014) looked closer at Langer's classic paper on plants and aging in a blogpost, and mentioned the need to scrutinize older, classical but small scale studies for their actual results. I was also inspired by Lee Jussim and his careful overview of past research in Social Perception and Social Reality (2012), as well as the work on scientific Urban legends (Rekdal, 2014) and the problem with the depiction of the classical Solomon Asch study in American Psychology text books(Griggs, 2015).

In my advanced social psychology class, students are required to pick a classical research paper and present the methods and statistical results. In the very first seminar, one of my students selected the paper by Srull \& Wyer, (1979). This is one of the ur-papers of Social Priming research. Two things struck me as we were going through the method. First, the methodological work is thoroughly put together with pretests and manipulation checks. Second, the samples are small. Eight individuals per cell in what, in essence, is a one-shot test.

I became interested in tracing this paper forward. What happened to this idea? Who cites this paper, and why? How could this add to our understanding of the development of the area of social priming which seems to have been the focus of much controversy the past few years (e.g. Special section on Behavioral priming and its replication, Perspectives on Psychological Science , 2014). On a more meta-scientific level, how could this technique be used to understand the role of highly cited ur-papers and how citations are used to bolster claims in the literature?

I originally posted my trace in a series of posts on my blog "... Not that kind of psychologist" (2015, beginning post listed in references), and uploaded an early public version of this paper on the Open Science Framework late 2016. The present paper is based on this work.

\section{On Lineages - Science as a Process and Why Tracing an Idea can be Fruitful}

David Hull (1988) proposed that science proceeds in an evolutionary manner. Ideas are generated, some are selected and passed on, and as they are passed on, the ideas change and develop. The ideas form in laboratories and in individual scientists heads, and are disseminated in papers and talks. Survival depends on not only the soundness of the work, but also whether the ideas are engaged with and cited. The process is both concerned with finding out what is true, as well as a social process. Ideas that are collaboratively engaged with in research groups (or demes), are more likely to survive than ideas with very few proponents, no matter how good they are.

Interestingly, in an evolutionary process like this, individual researchers need not be right, arguments need not be fleshier than straw, papers need not be balanced, and terminology need not 
Running head: DECENT AND MODIFICATION OF THE SOCIAL PRIMING PARADIGM

be fixed. Flawed human being can, in the process of arguing, mudslinging, collaborating and enthusiastic championing lead to better ideas, moving closer to something resembling truth.

Hull (1988) lays this out beautifully. His sample populations of scientists are, first, Darwin and those that championed his ideas of evolution, and later two groups of researchers working on models of biological classification. One point he makes is that to properly understand ideas one has to trace its lineage. Where did the idea (ostensibly) start, and how did it change as researchers engaged with it. This is easier said than done, as he points out early enough. The strands of science more resembles a felt than nice little tufts and trees of inheritance, which means that one necessarily need to simplify when tracing ideas, lest combinatorial explosion will take over.

\section{Present Work}

The present work traces the citations for Srull \& Wyer 1979 (from now on S \& W ). I think of it as a golgi-stain. It doesn't faithfully encompass all the work surrounding social priming, but like a golgi-stain, it could help us understand the development of what roughly can be considered social priming. Tracing can be thought of as a complement to comprehensive reviews and meta-analyses, in that it answers a somewhat different question, looking at the development of an idea rather than the robustness of a phenomenon.

\section{Short Summary of Srull \& Wyer (1979).}

S \& W aimed to test two main hypotheses: 1 ), the more you are primed with behaviors indicating a particular trait the more likely you are to later use that trait in your judgments, and 2) The activation caused by priming will decay over time.

The parts of the experiment are simple: a sentence-unscrambling task serving as the prime, an ambiguous vignette that is then rated. Each part is presented as a separate experiment. Srull \& Wyer do a thorough job setting up these parts. Through pre-testing they identify traits that are either strongly, ambiguously, or not related to hostility. From the ambiguously related traits, they create the Donald vignette. The strongly related and not at all related are then used for the trait measure.

The sentence unscrambling task was adapted from Costin* (1969, 1975 - not read directly) Originally, it was used as a measure, not as a manipulation. This is by now a familiar task. Participants are given a list of scrambled sentences. The task is to create a grammatical sentence using three out of the four provided words. The priming sentences are hostile, e.g. "leg break arm his". No matter how you put your sentence together, it will describe a hostile act.

To test their first hypothesis, they created priming questionnaires of two lengths: 30 or 60 items. These were also varied on proportion of hostile sentences: $80 \%$ or $20 \%$. This resulted in 4 conditions: a) 60 sentences, $80 \%$ (40 items) hostile b) 60 sentences, $20 \%$ ( 12 items) hostile c) 30 sentences, $80 \%$ ( 24 items) hostile d) 30 sentences, $20 \%$ ( 6 items) hostile. Notice that the priming is not subtle. Unscrambling 40 sentences describing hostile acts could not be unnoticed, but they are not interested in the subtle. To test the second hypothesis, participants read and rated the Donald vignette either immediately after priming, 1 hour after priming, or 24 hours after priming.

They ran 96 participants -8 in each cell. This is small, but the way the experiment is structured and analyzed makes the results believable. They titrated the dose of priming for 24 participants at 
Running head: DECENT AND MODIFICATION OF THE SOCIAL PRIMING PARADIGM

each level, and then tested a third of them immediately, a third after an hour and a third after a day. In the graphs of the results (not reproduced here) one can clearly see an ordering according to dose of prime, and a clear attenuation over time. They also only analyzed the data in a full-factorial ANOVA, without probing for simple effects or contrasts.

The effect on the trait rating is similar for both hostility and kindness, although appear weaker for kindness. In fact, it doesn't look like those that were primed with the fewest kind behaviors were influenced at all, as the curve is flat, but the low number of participants and lack of reported standard deviations leaves this an open question.

There is a reported main effect on survey length, but this is almost certainly attributable to the different mean frequency of target sentences in the two length conditions. The mean number of target sentences in the 60 item lists was 26, whereas for the 30 item lists the mean number of target sentences was 15 . The length manipulation is dropped in follow-up papers.

\section{Method: Trace}

\section{Extraction and Classification}

Papers citing S \& W were located in the Thomson Reuters Web of Science via the citation function. As of February 26, 2015, the paper had been cited 815 times in all data-bases. Of these, 805 were in the Web of Science core.

I extracted all the peer-reviewed papers that had cited S \& W for the first 5 years after its publication. This resulted in 53 papers. Only one paper could not be found: Semin, Chassein, Rosch \& Krolage (1984). This paper is in a Swiss journal and looks like it is in written in German. One paper, the third in the list with author "anonymous" is actually a simple reference list published in the journal.

From the remaining papers, I extracted the abstract and the citations in the text. From this information I noted down whether the paper was an experimental paper $(n=37)$, a theoretical paper $(n=8)$ or a review paper $(n=6)$. I then classified the papers as either extending the work experimentally $(n=11)$, related to the area but not about priming $(n=22)$, or if it was only obliquely related $(n=18)$. Table 1 shows a time-line of the papers, divided up in the three categories. 
Running head: DECENT AND MODIFICATION OF THE SOCIAL PRIMING PARADIGM

Table 1

Time-line for the retrieved papers, divided up into extending, related and oblique.

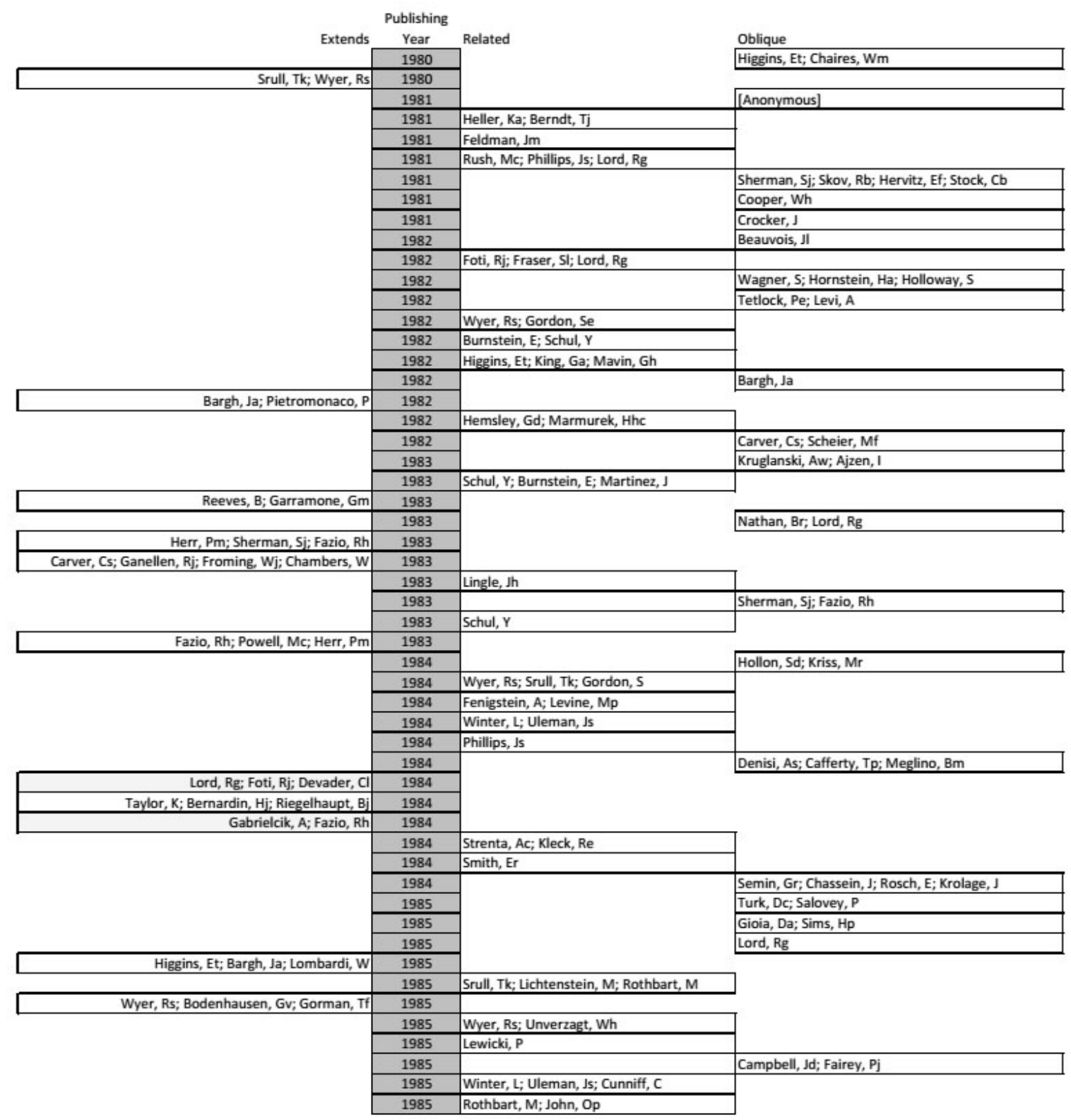

\section{Analysis of Citations}

For all papers I noted how many times S \& W were cited. Overall, there were 103 citations. In papers extending the work, the mean number of citations were 4.82 (4.15), with a median of 3 citations. For the related papers, mean number of citations were $1.24(0.61)$ with a median of 1 , whereas for the more oblique papers the mean were $1.41(0.59)$ with a median of 1 . Overall, the mean number of citations per paper was 2.10, with a median of one. For two papers, the citation was found in the reference list, but not in the actual body of the paper. Most likely this is due to editing problems in an era prior to citation management software. 
Running head: DECENT AND MODIFICATION OF THE SOCIAL PRIMING PARADIGM

Table 2

Number of citations in each paper, including placement of citations.

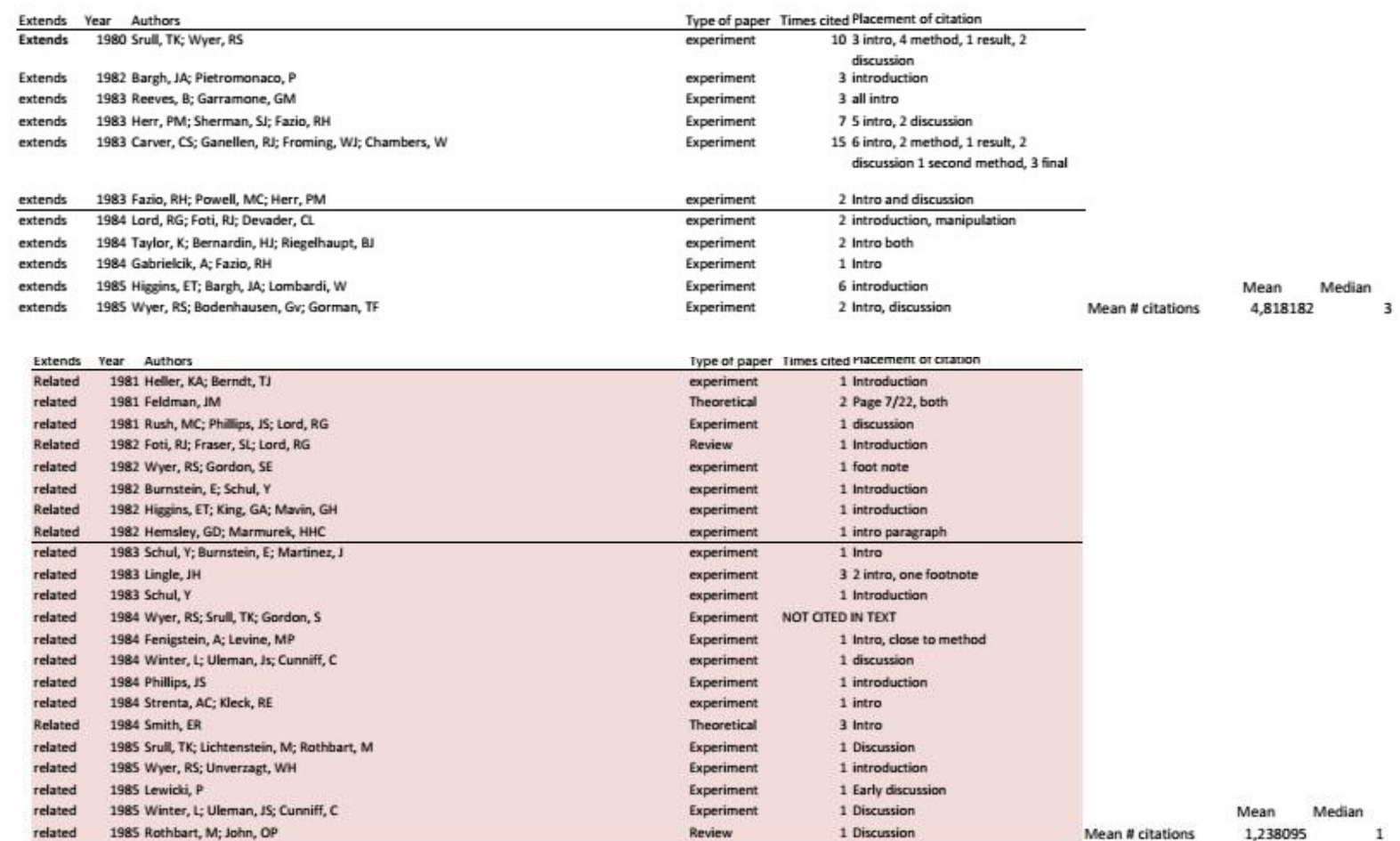

\begin{tabular}{|c|c|c|c|c|c|c|}
\hline Extends & Year Authors & \multicolumn{2}{|c|}{ Type of paper Times cited Placement of citation } & & & \\
\hline oblique & 1981 [Anonymous] & & & & & \\
\hline oblique & 1981 Sherman, SJ; Skov, RB; Hervitz, EF; Stock, CB & Experiment & 1 introduction & & & \\
\hline oblique & 1981 Cooper, WH & Review & 1 Page $12 / 27$ & & & \\
\hline Oblique & 1982 Wagner, S; Hornstein, HA; Holloway, 5 & Experiment & 1 introduction & & & \\
\hline oblique & 1982 Tetlock, PE; Levi, A & Review & 2 Page 6 and 12 of 21 & & & \\
\hline oblique & 1982 Bargh, Ja; Pietromonaco, $P$ & experiment & 1 Introduction & & & \\
\hline oblique & 1983 kruglanski, AW; Ajren, 1 & Theoretial & $\begin{array}{l}1 \text { page } 10 \text { of } 45 \text { in part on anchoring as } \\
\text { one mechunism }\end{array}$ & & & \\
\hline oblique & 1983 Nathan, BR; Lord, RG & Experiment & 1 discussion & & & \\
\hline oblique & 1983 Sherman, S; Fario, RH & Theoretical & 1 Page 26 of 39 & & & \\
\hline oblique & 1984 Hollon, SD; Kriss, MR & Theoretical & NOT CTED IN TEXT & & & \\
\hline oblique & 1984 Denisi, AS; Cafferty, TP; Meglino, BM & Experiment & 1 introduction & & & \\
\hline oblique & 1984 Semin, GR; Chassein, 1; Rosch, E; Krolaze, I & & & & & \\
\hline oblique & 1985 Turk, DC; Salovey, P & review & 1 page 4 of 15 & & & \\
\hline
\end{tabular}

Table 2 lists the papers with number of citations. The pattern seems reasonable. Work that is directly extending the research should cite the paper more often than papers that simply uses the citation as part of their arguments. It is also reasonable that the variation is larger for those papers that extend the research. It is interesting that only $21 \%$ of the papers citing the work are experimentally extending it, but it is unclear what this means considering that we have no norms about what percentage of citations are expected to be in papers extending a particular line of research.

Type of topic the citation supports. 
Running head: DECENT AND MODIFICATION OF THE SOCIAL PRIMING PARADIGM

The citations can be parsed into finer units. Some, especially the extending papers, used the citation when describing methodological parts of the work. Others referred back to the theoretical introduction. But there were also those that were more oblique. For some the citation was used as evidence for work in priming, whereas others simply used the reference as existence proof that other researchers were looking at cognitive processes.

I did a simple classification of the type of statement that was supported by each citation. Most of the citations discussed priming or, what I call, priming in other words, that is they describe that a construct has been activated which then influences subsequent cognitive tasks. Sixteen used the reference for impression formation, and 8 for "general cognitive processes". The categories are listed in table 3. I provide some example citations in figure 1.

All of the citations are correct, in that the statement they supported was a statement that can be reasonably attributed to the cited paper.

Table 3.

Classification of statement types supported by $S \& W$ citation. First column gives the overall frequency. The three following columns break the citations up across the three types of papers.

\begin{tabular}{lc|ccc} 
Type of statement supported by cite & \# cites & Extends & Related & Oblique \\
\hline priming & 28 & 15 & 8 & 5 \\
priming method & 20 & 20 & & \\
priming in other words & 18 & 9 & 2 & 7 \\
Impression formation & 16 & 2 & 8 & 6 \\
General cognitive processes & 8 & 2 & 3 & 3 \\
Trait inference spillover & 2 & & & 2 \\
Effect of prior evocation (mood, priming) on subsequent & & & & \\
changes in processing & 1 & & & 1 \\
Priming, Halo & 1 & & & \\
Priming, recency - frequency & 1 & 1 & & \\
Priming, assimilation vs contrast & 1 & 1 & & \\
Social judgment & 1 & & & \\
& & & & \\
Not extractable. & 5 & &
\end{tabular}

Below are some example of citations and their classification.

Example of "general cognitive process" citation.

However, because of recent theoretical and methodological developments in cognitive psychology, considerable effort is now being made to analyze these operations (Carlston, 1980, Ebbesen, 1980; Hastie \& Carlston, 1980; Srull \& Wyer, 1979; Wyer \& Carlston, 1979; Burnstein, \& Schul, 1982.)

Example of "priming in other words" citation 
Running head: DECENT AND MODIFICATION OF THE SOCIAL PRIMING PARADIGM

For example, Srull \& Wyer (1979) implicitly assumed that the accessibility of a trait concept affects judgments as a result of its influence on how behavioral information is interpreted and encoded at the time it is first acquired. Srull \& Wyer, 1980.

Example of "Impression formation" Citation

Once a judgment of a person has been made, this judgment is subsequently used as a basis for later inferences about the person, independent of the information upon which the judgment was originally based, e.g. Carlston, 1977; Srull \& Wyer 1979- Turk \& Salovey, 1985

\section{Paper topic and the frequency of citation.}

I was also wanted to see if there were a difference in frequency of citing $S \& W$ depending on whether the paper extended the work, was related to the work, or more oblique. Results are listed in Table 4. There were 18 papers that cited Srull \& Wyer multiple times, and 30 that cited them only once.

Table 4

Number of times cited by type of paper

\begin{tabular}{lcc} 
& Cited & $\begin{array}{l}\text { Cited once } \\
\text { multiple } \\
\text { times }\end{array}$ \\
\hline Extends & 1 & 10 \\
Related & 18 & 3 \\
Oblique & 11 & 5 \\
\hline
\end{tabular}

Clearly, papers that extend the work tend to cite the paper more frequently than those that do not, which is not surprising. The one that does it only once is the very short paper by Gabrielcik \& Fazio (1984)

\section{Citations: Alone or among others.}

Citations can either be alone (e.g. "Srull \& Wyer, 1979") or in a cluster (e.g. “... Hastie \& Carlston, 1980; Srull \& Wyer, 1979; Wyer \& Carlston, 1979;..."). Citations in clusters would indicate that there are multiple strands of evidence for a statement, but as shown above, that statement can be quite general as well as precise. Single citations could be due to specificity (particular methods or theories), but also due to a dearth of research in the area. Cluster citations could also be used to indicate demes - groups of researchers working on the same question - and could be useful for understanding the scientific process.

\section{Clusters vs. alone in the present study.}


Running head: DECENT AND MODIFICATION OF THE SOCIAL PRIMING PARADIGM

I checked whether there was more cluster type citations where $S \& W$ were cited only once than when $S \& W$ were cited multiple times. I coded the citations on how many accompanying citations there were (ranging then from 0 and up). There were 103 useful citations.

Table 5

Mean and median accompanying citations, separated by whether $S \& W$ were cited only once in the paper, or multiple times in the paper.

\begin{tabular}{lcc} 
& & $\begin{array}{l}\text { Cited } \\
\text { multiple } \\
\text { Accompanying citations }\end{array}$ \\
\hline Mean & $2,73(1,65)$ & $2,03(1,62)$ \\
Median & 2 & 1 \\
\hline
\end{tabular}

In papers that cite $S \& W$ only once, the citation is part of a cluster somewhat more than in papers that cite $S \& W$ multiple times but the difference isn't dramatic. The idea was that clustertype citations might be more common when the reference were used for more oblique purposes (existence of phenomenon) than when the reference was central for the research, but no clear conclusions can be drawn.

\section{Cluster citations as evidence of research demes.}

Papers that co-occur within clusters many times could possibly be considered belonging to the same deme (research groups that focus on a common research question). I looked at which papers were cited along with S \& W Two other papers stood out: Higgins Rholes \& Jones (1977) and Srull \& Wyer (1980) were co-cited 24 and 22 times respectively. The next most frequent Carlston (1980) was co-cited 5 times only.

\section{Discussion of Citation Analysis}

Overall, the analysis of the citations is illuminating. Scientific papers contain a number of statements that we like to back-up with citations, and the statements vary in importance for any particular work. It highlights, though, that a great deal of citations function mainly as back-up for arguments on a general level, with a minority of them functioning as support for crucial parts in the work. None of the citations here were inappropriate, nor did there seem to be any drift in meaning.

What it calls into question, though, is the reliance on number of citations as a proxy for impact or importance of work. It may be a rough proxy, but at some point becomes, perhaps more an indication of reputation and fame than of scientific importance. The citations combine the two factors Hull discusses - the scientific and the social. The solution is not to further parse the types of citations into different types, but to abandon it as some kind of meaningful measure in its raw form.

Perhaps the most interesting finding is who is cited along with $\mathrm{S} \& \mathrm{~W}$ more frequently, as that indicates who belong to the "deme" - the group most closely associated with this idea. It could be interesting to look further at the actual references and see who are referenced together, but it would be more efficient to do that with information-extracting software. 
Running head: DECENT AND MODIFICATION OF THE SOCIAL PRIMING PARADIGM

Classifications like this always depend on the rules of the classifier. The method I used extracting the sentence where the citation appears, and then classify according to apparent topic necessarily loses information such as whether this was more of an "existence" cite, or part of a more careful, multi-sentence argument. It would be fruitful to collect citations over a much longer trace. Understanding how cites are used in a more concrete fashion is important, considering how much weight we are giving to them.

\section{Extending Papers}

The 11 extending papers where relatively easy to determine. I did not include the very first paper citing S \& W, (Higgins \& Chaires, 1980) even though it investigates priming. It is not concerned with impression formation but seems to more be an extension of Higgins Rholes and Jones (1977). I also did not include a theoretical paper by Smith, which used Srull \& Wyer (1979) for theoretical reasoning, as I wanted to focus on experimental extensions. Table 6 lists some summary information for the extending papers.

Insert table 6 about here.

Overall, the papers give a diverse impression. All experiments follow the 2-experiment paradigm, where the priming and the measure are cast as separate experiments. However, of the 11 papers citing S \& W, only 4 can be thought of as direct extensions: Srull \& Wyer, 1980; Bargh \& Pietromonaco, 1982; Carver, Ganellen, Froming, \& Chambers, 1983 and Higgins, Bargh, \& Lombardi, 1985.

\section{Overview of primes, tasks and measures.}

Table 7 I show classification of the papers according to priming methodology, measure and construct primed. Note that there are 12 papers, as I include the original. 
Running head: DECENT AND MODIFICATION OF THE SOCIAL PRIMING PARADIGM

Table 7

Classification by Priming construct, Priming task, and Measure
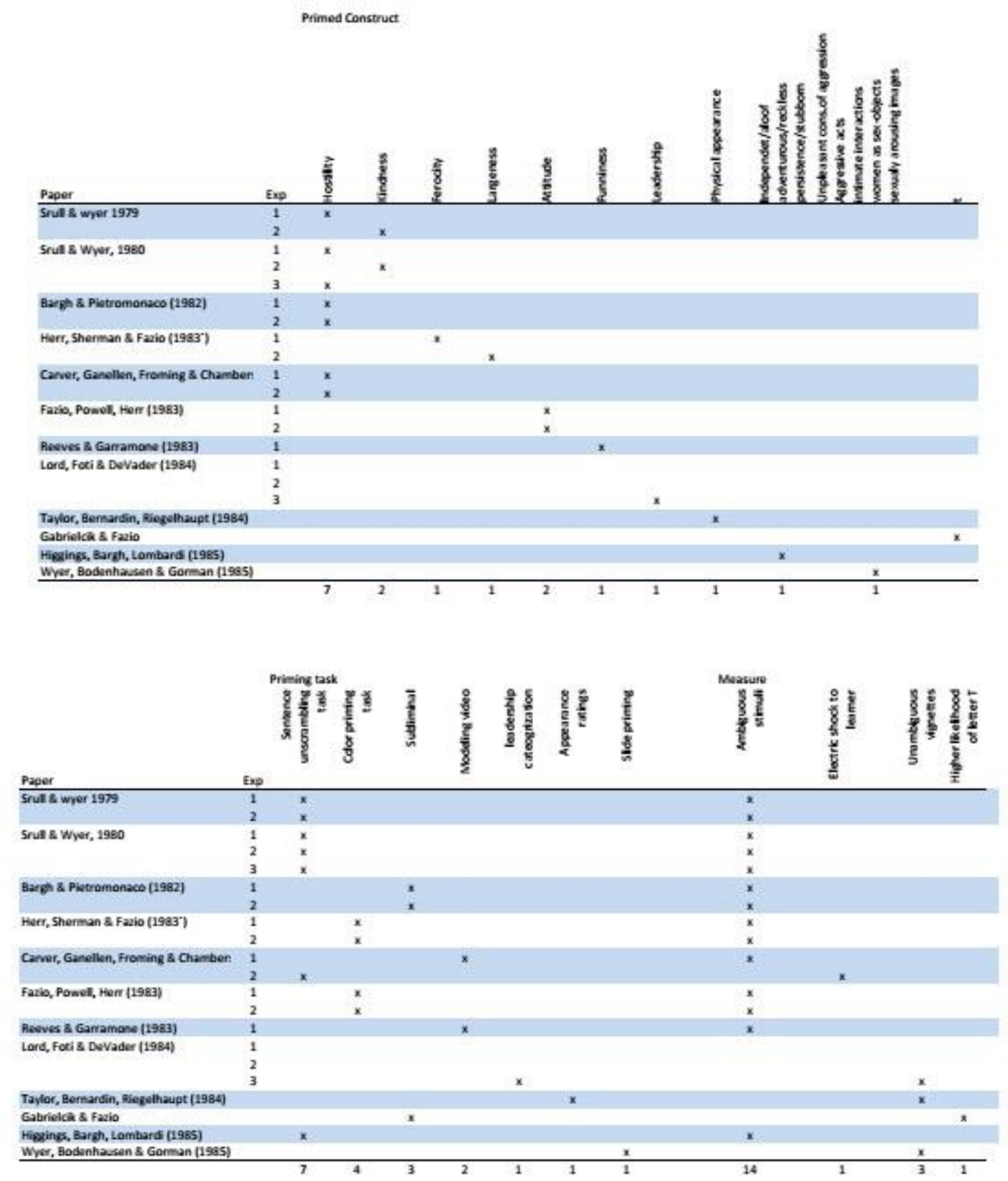

Seven experiments (4 papers) used some version of the sentence-unscrambling task. Four experiments ( 2 papers) used a color priming task that was first introduced by Higgins Rholes \& Jones 
Running head: DECENT AND MODIFICATION OF THE SOCIAL PRIMING PARADIGM

(1977). Three experiments (2 papers) used subliminal presentation; 2 used a modeling video. Finally one experiment/paper each uses leadership categorization, appearance ratings and slide priming. That is seven different types of priming methods across 12 papers.

The measures - when aggregated - are fewer. Fourteen experiments ( 8 papers) used ambiguous stimuli that are then rated. Three experiments (3 papers) use unambiguous vignettes. Finally one experiment used tendency to give electrical shocks, and one estimating the number of words with the letter $t$.

The constructs primed were more varied: Seven experiments (4 papers) primed Hostility. Two experiments (both S \& W papers) primed Kindness. One paper used Ferocity (exp 1) and Largeness (exp 2). One paper primed attitudes (positive or negative) in both experiments. One primed funniness. One primed Leadership and one physical appearance. Finally, there are two papers that prime multiple constructs.

\section{Priming tasks - a closer look.}

\section{Sentence unscrambling.}

The sentence unscrambling task was used in 4 papers ( 6 experiments). In three of the papers (Srull \& Wyer, 1979, 1980; Carver Ganellen \& Froming, 1983) comparisons were between at least one non-subtle and one subtle prime (see table 8). In the fourth paper, Higgins, Bargh \& Lombardo (1984) the prime was always subtle. Four items out of 20 were primes, with three of them being of one valence, and the final of the opposite. The comparison is between versions of subtle primes only. Note that there is no non-priming comparison condition in any of these experiments, so it is not clear whether the subtle priming condition actually primes anything.

Table 8

Frequency of priming stimuli in sentence unscrambling tasks.

Prime frequency, sentence unscrambling task.

\begin{tabular}{lrrrr} 
& cond 1 & cond 2 & Cond 3 & Cond 4 \\
\hline S \& W 1979 & $40 / 60$ & $24 / 30$ & $12 / 60$ & $6 / 30$ \\
S \& W 80 & $35 / 50$ & $15 / 50$ & & \\
C G F C & $24 / 30$ & $6 / 30$ & & \\
H, B, L & $4 / 20$ & & &
\end{tabular}

\section{Color-priming task.}

Two papers (4 experiments) used the color-priming task, originally used by Higgins, Rholes \& Jones (1977). Both papers came out of the Fazio lab. There are 10 trials. Four of these trials contain a priming word. As the ten trials are repeated, 8 out of 20 trials (40\%) contain the prime. The exception 
Running head: DECENT AND MODIFICATION OF THE SOCIAL PRIMING PARADIGM

here is for experiment 2, Fazio Powell \& Herr (1983), where the priming item appears only once (in position 7$)$ for both repetitions resulting in a subtle priming (10\%).

\section{Subliminal prime.}

Two papers presented the priming materials outside awareness. (Bargh \& Pietromonaco, 1982; Gabrielcik \& Fazio 1984). In both cases the priming materials were words, but the presentations, and the manipulations to ensure that participants were not aware of the semantic context is quite different. In addition, the differ in importance for the current project.

Bargh \& Pietromonaco presented words parafoveally. Presentation time was comparatively long (100 ms), but because they were presented parafoveally, participants were not consciously aware of the words. They used three conditions: $80 \%$ hostile, $20 \%$ hostile, and a non-hostile control.

Gabrielcik \& Fazio presented the words tachistoscopically (and thus, foveally). In a first series, the words were presented for $1 / 250 \mathrm{~s}$ (4 ms.), which is enough for participants to perceive the word. In the critical task, words were presented for $1 / 500 \mathrm{~s}$ (2 ms.) duration, where participants no longer perceive the words. In the priming condition, each word contained the letter $t$ (the construct to be primed), whereas the control condition consisted of all asterisks.

The primes here are subtle, in that participants are not aware of what they have been exposed to, but, in at least one condition, the sheer frequency of the to-be-primed construct is not subtle.

\section{Additional priming using words as primes.}

Two additional papers used words as their priming materials: Lord, Foti \& Devader (1984) and Taylor, Bernardin \& Riegelhaupt (1984). Neither one of the primed traits such as hostility or kindness as was done in the earlier ones. The Lord Foti \& Devader opportunistically used an earlier rating task as their prime, but the rating task was never constructed as a priming task. Thus it is neither subtle, or strong, but opportunistic. 8/25 10/25 6/25. Leadership. The task in Taylor et all was to rate 25 physical traits on an irritating-appealing dimension. The prime here is, in essence, an attitude rehearsal about physical trait. Since all of them were about physical traits, the priming is not subtle.

\section{Films and pictures.}

Two experiments used films for their primes (Carver et al 1983, exp 1; Reeves \& Garamone, (1983), and one used slides depicting the to-be-primed construct (Wyer, Bodenhausen \& Gorman). We are now moving into methods where it is unclear what is activated - a construct, or an emotional state, or (most likely) a mixture of both. The present author has published work teasing apart the effects of emotion and priming (from an emotion-induction perspective) in some later work (Niedenthal, Innes-Ker, \& Margolin, 1999; Innes-ker \& Niedenthal, 2002). Still, it clearly falls into the type of methods where something is activated, and the biasing effect on a subsequent unrelated task is rated.

Carver et al (1983) cast theirs as a modeling experiment in the Bandura tradition (e.g. Bandura, Ross \& Ross, 1961), and presented their participants with either a clip where a boss berates a secretary, or a clip where both are behaving professionally. 
Running head: DECENT AND MODIFICATION OF THE SOCIAL PRIMING PARADIGM

Reeves and Garamone (1983) were interested in whether exposure to everyday sitcoms would alter children's ratings of other people, and exposed children in grade, 2, 4 and 6 to a 10 minute video of 7 sequences from TV sit-coms that had been rated as the most funny in an earlier test.

Showing films is more of a continuous presentation, than something in discrete proportions, but I would not consider these subtle or surreptitious.

The slide-presentation can be thought of in more discrete terms, with proportions of priming materials, but the images are not subtle. The proportion of primes were $6 / 20(30 \%)$, but I would doubt that being exposed to images of violence or erotica would be as subtle as being exposed to a hostile sentence, or a small set of large animals. In fact, Lang et al. (2008) have used strong images to evoke emotions in their IAPS materials.

\section{Summary Priming tasks.}

To summarize, the priming tasks across these 12 papers are quite heterogeneous. They vary in dose (intense to subtle), they vary in modality of delivery (presentation of words - on paper or computer, rating of words, films, slides), they vary in duration of delivery (self-paced through subliminal), and they vary in construct. They frequently seem to prime, if by that we mean that something is activated that is then biasing subsequent responses but, as mentioned, it is not clear that what is activated is some kind of construct and not some function of affect or both.

Granted, this is not an exhaustive collection of priming studies during this 5 year period, but it is an exhaustive study of those that cite $S \& W$. The variety of priming methods inspired by this paper is remarkable, and I think something that needs to be looked at carefully.

\section{Primed constructs.}

The primed constructs are also quite varied. Several clearly have an affective component (e.g. Hostility, kindness, the positive or negative valence evoked by an attitude object), but there are also some that are less clearly affect laden such as ferocity, largeness, leadership, physical appearance, frequency of letter $t$. In the majority of papers, only one construct is primed in any one experiment. However, the two last papers (Higgins et al., 1985, Wyer et al, 1985) prime multiple constructs, although mostly between participants. Higgins et al. (1985) specifically wanted to include more than one construct in order to extend the priming, and thus primes independent/aloof, Adventurous/reckless and Persistent/stubborn. For Wyer et al. there were 6 different priming conditions: Unpleasant consequences of aggression, aggressive acts, intimate interactions, women as sexual objects, and two versions of sexually arousing photographs of women (presumed sexually arousing to men). Considering that some of these types of images (dead people, naked women) are used for investigating affective reactions (e.g. IAPS, Lang 2008) it is likely that they not only bring the cognitive concepts to mind but may also induce affective responses. One must recall, though, that this was not a clear distinction at the time.

This early in the trace there doesn't seem to be a great deal of systematicity in probing how priming works in social domains. There are a limited number of traits primed through descriptive actions.

Measures. 
Running head: DECENT AND MODIFICATION OF THE SOCIAL PRIMING PARADIGM

The measures are, in some ways, fewer. A great deal of them consists of vignettes, mostly ambiguous, that are then rated via likert scales on a handful of dimensions.

\section{Donald vignette.}

Srull \& Wyer (1980), Bargh \& Pietromonaco (1982) and Carver, Ganellen et al (1983), used the Donald story, along with the trait ratings on the descriptive and evaluative dimensions. Interestingly, Carver et al mentioned they needed to tone the Donald story down, as he read as more hostile in Florida than in Illinois. It is unclear whether Bargh et al and Carver et al used both vignettes created by $S \& W$.

Because the Donald Vignette and the trait ratings were used in several studies, it is interesting to look at how the different types of priming compared in how participants rated Donald.

Table 9

Mean hostility ratings of the Donald vignette, by type of prime. (hostility only)

\begin{tabular}{|c|c|c|c|c|c|c|c|}
\hline Proportion & $S \& W$ & Proportion & & Proportion & & Priming & Carver et \\
\hline Hostile & 1979 & Hostile & S \& W 80 & Hostile & B \& P 82 & type & \\
\hline $6080 \%$ & 9,7 & $5070 \%$ & 6,9 & $80 \%$ & 7,47 & Hostile & 6,47 \\
\hline $3080 \%$ & 8,5 & $5070 \%$ & 7,1 & $20 \%$ & 6,75 & Neutral & 5,86 \\
\hline $6020 \%$ & 6,7 & $5030 \%$ & 5,2 & $0 \%$ & 6,99 & & \\
\hline $3020 \%$ & 5,7 & $5030 \%$ & 5,5 & & & & \\
\hline
\end{tabular}

For the Two Srull \& Wyer $(1979,1980)$ papers, I only used the means from the immediate ratings. (Those means were estimated from the graphs in the papers). Looking at the ratings here, it is clear that the amount you are exposed to the priming matters. The more instances of the hostile behaviors in the sentence-unscrambling task, the more hostile (and less non-hostile) you will rate Donald. But, when the mix is fairly low, the ratings will hover around the mid-point of the scale. In the subliminal prime (Bargh \& Pietromonaco (1982), there seem to be very little difference between the low and none, and somewhat more for the high primed. The Carver et al (1983) used modeling instead, and although there is a difference in ratings, it doesn't seem to be as big as for the two Srull \& Wyer papers.

In an attempt to make effect-size comparison, I checked the estimated effect size using Schimmack's (2016) R-index calculation sheet. For Bargh \& Pietromonaco (1982) estimated d is 0.51, and for Carver et al $d=0.53$. The effect size for the two Srull \& Wyer $(1979,1980)$ papers are much more difficult to estimate, as the main effect of priming proportion includes data across all delay types. In both instances the estimate is $d=1.17$, which seems unreasonably high for a social psychology experiment. It may be due to the small sample sizes, as this tends to lead to an overestimation of effect size (e.g. Francis, 2017)

All four papers used both the descriptive and evaluatively related trait measures. Priming affected the evaluatively related measure at an attenuated strength for the three first papers, but there was no evidence for the spillover in the Carver et al (1983) paper.

\section{Other ambiguous vignettes.}


Running head: DECENT AND MODIFICATION OF THE SOCIAL PRIMING PARADIGM

Reeves \& Garamone (1983) also relied on an ambiguous story, about Andy, who is a schoolchild and who may (or may not) be funny. The character is then rated on 25 different trait adjectives, also via likert scales.Fazio et al (1983) used an ambiguous vignette about Ted, where the ratings were on what may have motivated him to participate in an experiment - also on likert scales. Higgings, Bargh \& Lombardi (1985) used short ambiguous vignettes depicting one of three types of traits. Rather than rating, participants named the trait that described the individual, and separate judges are then rating how close this naming is to any of the positive or negative trait synonyms for the intended trait.

\section{Ambiguous stimuli that are not vignettes.}

Herr Sherman \& Fazio (1983) created imaginary animals that were to be rated on three dimensions related to ferocity or 3 dimensions related to size.

\section{Vignettes that are not ambiguous.}

For three experiments, the vignettes are not ambiguous. The Lord, Foti \& Devader (1984) study (where priming was opportunistic) used 3 vignettes, where one was prototypical, one neutral and one anti-prototypical of good leaders. This would leave very little room for priming to bias ratings, so perhaps it is not strange that no priming effect was found.

In the Taylor et al (1984) study, two target teachers were set up to either be clearly warm/relaxed or cold/rigid. The measure of interest was not the traits, but ratings of physical appearance which has been shown to be influenced by the halo effect. The test was whether making ones preferences on physical appearance more salient in a separate task might attenuate the halo effect.

The rape-depictions in Wyer et al (1985) were also not ambiguous. The variables here were instead whether it was an acquaintance or stranger rape, and whether or not the victim resisted. The vignettes were rated on a number of dimensions that were then separately analyzed. Note also that the presentations here are repeated measures - one of the few instances in this trace (the other one being (Herr, Sherman, \& Fazio, 1983). The ratings were, again, on likert scales across several dimensions.

\section{Other measures.}

One measure was behavioral. Carver et al (1983) asked participants (primed with the sentence unscrambling task) to serve as "teachers" in a Milgram inspired task - shocking a learner who made errors. Finally, in the frequency task used by Gabrielcik \& Fazio (1984) it was simply rating which letter was more frequent in the English language.

\section{Summary.}

Summary: Most of the measures here are one shot. It is rare that participants are asked to rate more than one thing that may be influenced by the prime. The exceptions are Herr, Sherman \& Fazio (1983) where each participant rated 4 real and 2 imaginary animals, and the ratings of the rapedepictions in Wyer, Bodenhausen \& Gorman (1984). Mostly participants made ratings on likert scales that were then aggregated, but for Higgins, Bargh \& Lombardi (1980), participants simply stated a 
Running head: DECENT AND MODIFICATION OF THE SOCIAL PRIMING PARADIGM

trait-word that was then judged. With these types of designs, especially the last one with ample opportunity for adding error, it is important to look at the sample sizes.

\section{Sample sizes.}

I calculated the mean, median and standard deviation of sample sizes and cell sizes, leaving out the Lord Foti \& Devader paper as it produced no effect.

Table 10

Central tendency and spread of Sample sizes and cell sizes.

\begin{tabular}{lrr}
\multicolumn{2}{c}{$\mathrm{N}$} & $\mathrm{n}$ \\
\hline Mean & 90,13 & 17,53 \\
Median & 88,00 & 15,25 \\
SD & 41,14 & 10,08
\end{tabular}

Sample size always refers to number of participants. This works well, as most of the measures are between participants. It is also important to relate sample size/cell size to the design. A cell-size of 8 may work fine when the design titrates the dosage of the treatment, as in the original S \& W paper. It is less convincing when they test, as they do in Srull \& Wyer 1980, whether the evaluation increases across delay. It is also more problematic when the priming dosage is low, as in Higgins, Bargh \& Lombardi.

The cell sizes are still likely on the low side for social psychology. A particularly interesting example is the Herr et al. (1983) work on assimilation/contrast. Results in the first experiment were somewhat inconclusive. In the second experiment, the sample size was doubled, and here the evidence reached significance.

Perhaps the two studies with the low $\mathrm{n} /$ cell are of most concern are the two last: Higgins, Bargh \& Lombardi (1985), and Wyer, Bodenhausen \& Gorman (1985). To begin with the last, each priming condition contains 5 men and 5 women. They do rate 5 vignettes on several dimensions, but only 4 of those vignettes are used, and in those vignettes, there really are only two instances that can be considered repeated measures. Yet, men and women are compared across priming conditions. To their credit, they do mention that the work is exploratory. It certainly sets up areas that are ready to probe with larger sample sizes, and perhaps that has been done. The paper has been cited xx times.

The Higgins, Bargh \& Lombardi (1985) work is more problematic. Their stated purpose is to discriminate between thee models of priming. The critical part, they claim, is comparing how participants behave when rating ambiguous stories immediately after priming or after some delay. There are 30 participants in each delay condition, but each delay condition is really an amalgam of 6 different priming conditions with 5 participants each. There are 3 different constructs primed, and within each construct, participants were primed by both a negative and a positive variant of the construct, and at a very low frequency. The response was also a one-shot verbally stated impression that was later judged as how well this response corresponded with a synonym of either the positive or negative trait. There are so many opportunities for variation and error introduced in this design, 
Running head: DECENT AND MODIFICATION OF THE SOCIAL PRIMING PARADIGM

that I would not use the results to distinguish between models. In fact, I would be surprised if this replicated.

\section{Reporting of statistics: $\mathbf{R}$-index.}

I wanted to do some more formal testing of the results. A meta-analysis is not feasible, as the topic and methods of the studies are so heterogeneous that the result would be nonsensical. A pcurve is also not feasible for similar reasons (although I did attempt one - it suggests that there is some evidential value in the research). I settled on using the R-index as a reasonable tool as it is designed to look at some arbitrary (although a-priori well defined) body of work to estimate reproducibility (roughly testing whether power as revealed by the \% of experiments yield a positive result against the median of the post-hoc power. See Schimmack 2016).

I set out to collect as much of the statistics I could from the papers. The reporting is surprisingly varied. In two instances ( $\&$ \&, 1980 , exp $1 \& 2$, and Bargh \& Pietromonaco, 1982) the ANOVA tables are published. This is really useful for researchers that are interested in summarizing earlier work. The only paper that reports standard deviations and a measure of effect size is Taylor, Bernardin \& Riegelhaupt. In most cases I retrieved the inferential statistics from the text. I decided to use the information from all papers except the Lord, Foti \& DeVader (1984), as there was no effect reported.

Perhaps the most difficult judgment was to decide which of the tests in the two $S \& W$ papers would be considered the Focal Hypothesis for the R-index. (I ended up using a large number of them). I created two different R-indices: One for the full set of studies, one for those I deemed most directly extending $S \& W$. 
Running head: DECENT AND MODIFICATION OF THE SOCIAL PRIMING PARADIGM

Table 11: $R$-index replication

\begin{tabular}{|c|c|c|c|c|c|}
\hline & Success Rate & $\begin{array}{l}\text { Obs. } \\
\text { Power }\end{array}$ & $\begin{array}{l}\text { Inflation } \\
\text { Rate }\end{array}$ & R-Index & $\begin{array}{l}\text { Median } \\
\text { FHT } \\
r(\mathrm{~N}, \mathrm{~d})\end{array}$ \\
\hline All & 0,808 & 0,607 & 0,201 & 0,405 & $-0,510$ \\
\hline Sub-set & 0,883 & 0,710 & 0,173 & 0,536 & 0,074 \\
\hline
\end{tabular}

Following Schimmack's suggestion, when looking at all results, there is a suggestion of an inflation, and reduced replicability, whereas looking at those extending $S \& W$, suggest that there is higher reproducibility, but not by much.

\section{Discussion of Results.}

The papers that directly test priming are strikingly heterogeneous. Five papers out of the 11 extends S \& W (Srull \& Wyer, 1980; Bargh \& Pietromonaco 1982; Carver et al 1983 and to some degree Higgins, Bargh \& Lombardi 1980). Herr, Sherman \& Fazio (1983) engages with the theoretical account (why would priming lead to assimilation) but their primed construct is not a human behavior but ferocity/size of animals. The remainder of the papers seems like the authors have been inspired by the priming account, and then adapted it to their own area of inquiry. This is not a problem, of course. It is possible that this happens whenever new ideas are introduced - a kind of transient where offshoots may result in their own branches (if fruitful), whereas the main branch could stabilize into stronger probing of the phenomenon. This is something that future traces would look at and would mostly be interesting from a meta-science perspective.

The number of participants in each cell is low. However, let's not be whiggish when judging past experiments. The number of participants seems to be within a standard that was set at the time. As anybody knows that have read Kuhn (1962), science includes a number of practices that have evolved tacitly and practically, rather than having been reasoned. When perusing Schimmacks Blog (2016), I came across this quote from Roy Baumeister (2016):

"When I was in graduate school in the 1970s, n=10 was the norm, and people who went to $\mathrm{n}=20$ were suspected of relying on flimsy effects and wasting precious research participants."

This may have been a reasonable stance at that time, but as research developed and changed, the norms for sample sizes did not even as more subtle effects was pursued, and as we know, power is related to number of observations and effect size.

The range of priming strength and methods is also remarkable; from the extremely strong (e.g. 48 out of 60 sentences) to the very weak ( 1 priming instance, shown twice) to that outside awareness. The use of films and pictures with emotional content should, perhaps, be considered falling under emotion induction and not priming, but that discussion did not take place until a decade later. 
Running head: DECENT AND MODIFICATION OF THE SOCIAL PRIMING PARADIGM

The measures also vary. Ratings of individuals behaving ambiguously dominate. Likert scale ratings of traits dominate, but they range from multiple ratings that are subsequently aggregated into an index, to one-shot ratings of a single trait. There is one behavioral measure (Carver et al 1983). A sample of 11 papers is not enough to do a careful comparison of measurement, but this would be interesting.

A short trace like this cannot say anything conclusive about the phenomena usually considered Social Priming (see Cesario \& Jonas, 2014 why one should be careful about using such an allencompassing term), but it is still informative. Exposing participants to a large amount of priming stimuli does have face-validity to it, as does exposing participants to modeling films. The more subtle kinds - the subliminally presented, or those where the priming materials are a low percentage of all presentations - seem more uncertain. In some instances (Herr et al 1983) the analysis of results could just as well be compatible with the null hypothesis. In the Higgins, Bargh \& Lombardi (1985), the very low $\mathrm{N}$, and the uncertainty inherent in their procedure the results may very well be a fluke.

\section{General Discussion Contribution of time-line method}

In Psychology, we do not spend much time looking at how our ideas develop and change over time. We build on earlier research, by assembling introductions where published results are used as arguments, or by aggregating work in either narrative reviews or meta-analyses - but none of the methods considers the provenance of our ideas and how time alters them. The time-line trace borrows from historical methods, and allows us to get some handle on both how ideas develop (possibly becoming more factual), and how the social interaction of researchers help shape these ideas. This is different from the aggregates, where time has simply been removed.

In this relatively short trace, it is evident that the majority of the articles citing S\&W do not address priming, but cite the paper for other types of research or theoretical issues. For those that extend the work, the directions seem non-systematic. It is almost as researchers have noticed an interesting phenomenon and asked whether it pertains to their own research domain. A general question is then - would we see similar patterns when we trace other influential papers?

The trace can be used to better understand the various functions of citations. In this trace alone the role of the citation ranges from existence citations (someone has already worked on this interesting phenomenon) to important functional citations (e.g. making use of the theories and methods in the paper). Importantly, the functional (extending) citations are the minority of citations. It is a useful complement to other types of citations research (e.g. Hanel \& Haase, 2017).

A trace can also be used to identify research demes - actors that work on a particular research question either cooperatively or in competition. This can help us further understand how research proceeds - which is of interest from a meta-scientific perspective. It may also allow us to identify whether the research question is pursued by multiple demes with somewhat different interests which might give rise to the important kind of critique that are useful for advancing knowledge (see Hull, 1988, Mercier \& Sperber, 2011), or, if the question is pursued by a single group with not enough independent replications and extensions to critically evaluate the effects.

Finally, a trace can also make us better understand the direction a research question has taken. For example, anecdotally I have heard several times that social priming needs to be subtle - 
Running head: DECENT AND MODIFICATION OF THE SOCIAL PRIMING PARADIGM

either outside awareness, or very mild so that participants are not aware of the prime. But, the prime in $\mathrm{S} \& \mathrm{~W}$ is not subtle. What participants are unaware of is instead the connection to the subsequent tests. The subtle prime is instead a boundary condition, investigated rather early on in the trace, and thus the notion of subtlety may in part be due to idiosyncratic and historic issues.

I hope I have demonstrating that tracing and carefully scrutinizing the decent and modification of a citation can be a useful complement to other aspects of aggregating research. The method I have used is time-consuming, but automating some of the aspects is not difficult, and would make it easier to undertake larger traces. The insights are important not only from a meta-science perspective, but also for understanding how some of our more important ideas have developed. We do need more of these types of aggregates of research in order to better understand which ones of our findings are robust, as well as what practices of research we need to change and modify to ensure that we can build on earlier work. 
Running head: DECENT AND MODIFICATION OF THE SOCIAL PRIMING PARADIGM

\section{References}

Bargh, J. A., \& Pietromonaco, P. (1982). Automatic information processing and social perception: The influence of trait information presented outside of conscious awareness on impression formation. Journal of Personality and Social Psychology, 43(3), 437-449. http://doi.org/10.1037/0022-3514.43.3.437

Bandura, A., Ross, D., \& Ross, S. A. (1961). Transmission of aggression through imitation of aggressive models. The Journal Of Abnormal And Social Psychology, 63(3), 575-582. doi: $10.1037 / \mathrm{h} 0045925$

Baumeister, Roy F. (2016) Charting the future of social psychology on stormy seas: Winners, losers, and recommendations. Journal of Experimental Social Psychology, 66, 153-158. https://doi.org/10.1016/j.jesp.2016.02.003

Carver, C. S., Ganellen, R. J., Froming, W. J., \& Chambers, W. (1983). Modeling: An analysis in terms of category accessibility. Journal of Experimental Social Psychology, 19, 403-421. http://doi.org/10.1016/0022-1031(83)90019-7

Cecario, J \& Jonas, K (April 9 2014). Expectations of replicability and variability in priming effects, Part I: Setting the scope and some basic definitions. retrieved from http://osc.centerforopenscience.org/2014/04/09/expectations-1/

Costin, F (1969). The scrambled sentence test: A group measure of hostility. Educational and Psychologcal Measurement, 29, 461-468.

Costin F. Measuring hostility with the srambled sentence test. In L.K. Verma \& C. Bagley (Eds.), Race and education across cultures. London: Heineman, 1975.

Coyne, James. (November 5 2014). Re-examining Ellen Langers Classic study giving plants to nursing home residents [Blog post]. Retrieved from

http://blogs.plos.org/mindthebrain/2014/11/05/re-examining-ellen-langers-classic-studygiving-plants-nursing-home-residents/

Fazio, R. H., Powell, M. C., \& Herr, P. M. (1983). Toward a process model of the attitudebehavior relation: Accessing one's attitude upon mere observation of the attitude object. Journal of Personality and Social Psychology, 44(4), 723-735.

http://doi.org/10.1037/0022-3514.44.4.723

Francis, Gregory. (207) Equivalent statistics and data interpretation . Behavior Research Methods 49, 1524-1538. https://doi.org/10.3758/s13428-016-0812-3

Gabrielcik, Adele \& Fazio, Russell H. (1984). Priming and frequency estimation. A strict test of the availability heuristic. Personality and Social Psychology Bulletin, 10(1), 85-89. https://doi.org/10.1177/0146167284101009

Greenwald, a G., McGhee, D. E., \& Schwartz, J. L. (1998). Measuring individual differences in implicit cognition: the implicit association test. Journal of Personality and Social 
Running head: DECENT AND MODIFICATION OF THE SOCIAL PRIMING PARADIGM

Psychology, 74(6), 1464-80. Retrieved from

http://www.ncbi.nlm.nih.gov/pubmed/9654756

Griggs, R. a. (2015). The Disappearance of Independence in Textbook Coverage of Asch's Social Pressure Experiments. Teaching of Psychology, 42(2), 137-142. http://doi.org/10.1177/0098628315569939

Hanel, P. H. P., \& Haase, J. (2017). Predictors of Citation Rate in Psychology: Inconclusive Influence of Effect and Sample Size. Frontiers in Psychology, 8, 1160. http://doi.org/10.3389/fpsyg.2017.01160

Herr, P. M., Sherman, S. J., \& Fazio, R. H. (1983). On the consequences of priming: Assimilation and contrast effects. Journal of Experimental Social Psychology, 19, 323340. http://doi.org/10.1016/0022-1031(83)90026-4

Higgins, E. T., Bargh, J. A., \& Lombardi, W. J. (1985). Nature of priming effects on categorization. Journal of Experimental Psychology: Learning, Memory, and Cognition, 11(1), 59-69. http://doi.org/10.1037/0278-7393.11.1.59

Higgins, E. T., \& Chaires, W. M. (1980). Accessibility of interrelational constructs: Implications for stimulus encoding and creativity. Journal of Experimental Social Psychology, 16, 348-361. http://doi.org/10.1016/0022-1031(80)90027-X

Higgins, E. Tory, Rholes, William S., \& Jones, Carl R. (1977). Category accessibility and impression formation. Journal of Experimental Social Psychology, 13 (2), 141-154. https://doi.org/10.1016/S0022-1031(77)80007-3

Hull, David. (1988). Science as a Process. Chicago, IL, US: The University of Chicago Press.

Innes-Ker, Åse. (March 11, 2014) Tracking Srull and Wyer (1979): Bargh \& Pietromonaco, 1982. [Blog Post] Retrieved from https://asehelene.wordpress.com/2015/03/11/trackingsrull-wyer-1979-bargh-pietromonaco-1982/

Innes-Ker, Å., \& Niedenthal, P. M. (2002). Emotion Concepts and Emotional States in Social Judgment and Categorization, Journal of Personality and Social Psychology, 83(4), 804816. http://doi.org/10.1037//0022-3514.83.4.804

Jarrett, Christian (2008). Foundations of sand? The psychologist, 28, 756-759

Jussim, L. (2012). Social perception and social reality: Why accuracy dominates bias and self-fulfilling prophecy. New York, NY, US: Oxford University Press.

Kuhn, Thomas S. (1962). The structure of scientific revolutions. Chicago :University of Chicago Press

Lang, P.J., Bradley, M.M., \& Cuthbert, B.N. (2008). International affective picture system (IAPS): Affective ratings of pictures and instruction manual. Technical Report A-8. University of Florida, Gainesville, FL. 
Running head: DECENT AND MODIFICATION OF THE SOCIAL PRIMING PARADIGM

Lord, R. G., Foti, R. J., \& De Vader, C. L. (1984). A test of leadership categorization theory: Internal structure, information processing, and leadership perceptions. Organizational Behavior and Human Performance, 34, 343-378. http://doi.org/10.1016/00305073(84)90043-6

Mercier, H., \& Sperber, D. (2011). Why do humans reason? Arguments for an argumentative theory. Behavioral and Brain Sciences, 34(2), 57-74. doi:10.1017/S0140525X10000968

Milgram, S. (1963). Behavioral Study of obedience. The Journal Of Abnormal And Social Psychology, 67(4), 371-378. doi:10.1037/h0040525

Niedenthal, P. M., Innes-Ker, A. H., \& Margolin, J. (1999). Emotional Response Categorization. Psychological Review, 106(2), 337-361.

Nisbett, R. E., \& Wilson, T. D. (1977). The halo effect: Evidence for unconscious alteration of judgments. Journal Of Personality And Social Psychology, 35(4), 250-256. doi:10.1037/0022-3514.35.4.250

Reeves, B. \& Garramone, Gina M (1983). Television's Influence on children's encoding of person information. Human Communication Research 10(2), 257-268.

Rekdal, O. B. (2014). Academic urban legends. Social Studies of Science, 44(4), 638-654. http://doi.org/10.1177/0306312714535679

Schimmack, Ulrich (2016, January 31). A revised introduction to the R-index [Blog Post] https://replicationindex.wordpress.com/2016/01/31/a-revised-introduction-to-the-r-index/

Schimmack, Ulrich (2016, April 18). Replicability report no. 1: Is ego-depletion a replicable effects? [Blog Post] retrieved from https://replicationindex.wordpress.com/2016/04/18/is-replicability-report-egodepletionreplicability-report-of-165-ego-depletion-articles/

Semin, Chassein, Rosch \& Krolage (1984). Social psychological considerations concerning the limits of meaning of psychometric personality models, Psychologie Schweizerische Zeitschrift fur Psychologie und ihre Andwendungen, 43, 75-90.

Shakil, Amna \& Schimmack, Ulrich (2015). Using the R-index to detect questionable research practices in ssri studies. [Blog post] retrieved from https://replicationindex.wordpress.com/2015/08/05/using-the-r-index-to-detectquestionable-research-practices-in-ssri-studies/

Special Section on Behavora Priming and its Replication. (2014)Perspectives on Psychological Science,9(1) 40-80

Srull, T. K., \& Wyer, R. S. (1979). The role of category accessibility in the interpretation of information about persons: Some determinants and implications. Journal of Personality and Social Psychology, 37(10), 1660-1672. http://doi.org/10.1037/0022-

3514.37.10.1660 
Running head: DECENT AND MODIFICATION OF THE SOCIAL PRIMING PARADIGM

Srull, T. K., \& Wyer, R. S. (1980). Category accessibility and social perception: Some implications for the study of person memory and interpersonal judgments. Journal of Personality and Social Psychology, 38(6), 841-856. http://doi.org/10.1037/00223514.38.6.841

Stafford, Tom (2014). The perspectival shift: how experiments on unconscious processing don't justify the claims made for them. Frontiers in Psychology, 5: 1067 doi: 10.3389/fpsyg.2014.01067

Taylor, K., Bernardin, H. J., \& Riegelhaupt, B. J. (1984). Halo Error: an Assessment of Priming As a Reduction Technique. Perceptual and Motor Skills, 59, 447-457. http://doi.org/10.2466/pms.1984.59.2.447

Wyer, R. S., Bodenhausen, G. V, \& Gorman, T. F. (1985). Cognitive mediators of reactions to rape. Journal of Personality and Social Psychology, 48(2), 324-338.

http://doi.org/10.1037/0022-3514.48.2.324

*The Costin scrambled sentence test appears to have been a measure rather than a manipulation.

They thank him for providing his materials. 
Running head: DECENT AND MODIFICATION OF THE SOCIAL PRIMING PARADIGM

Table 6

classification of extending papers

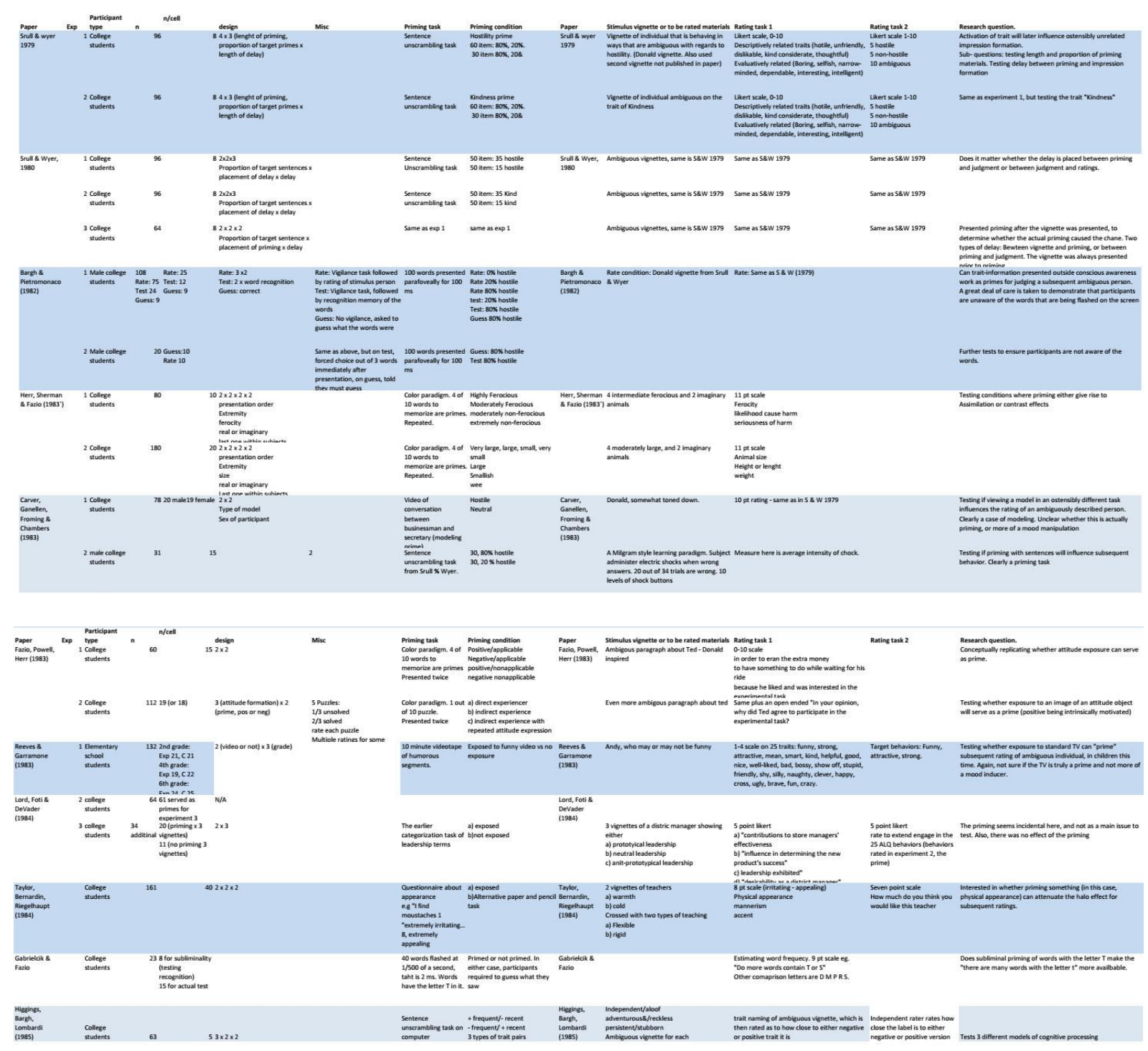

